The Journal of Laryngology \& Otology

http://journals.cambridge.org/JLO

Additional services for The Journal of Laryngology \& Otology:

Email alerts: $\underline{\text { Click here }}$

Subscriptions: $\underline{\text { Click here }}$

Commercial reprints: Click here

Terms of use : $\underline{\text { Click here }}$

\title{
Development of cavernous haemangioma following radical chemo- radiotherapy for nasopharyngeal carcinoma
}

J R Ellenbogen, S M Joshi and N Kitchen

The Journal of Laryngology \& Otology / Volume 123 / Issue 08 / August 2009, pp 925 - 927

DOI: 10.1017/S0022215108003605, Published online: 17 September 2008

Link to this article: http://journals.cambridge.org/abstract_S0022215108003605

How to cite this article:

J R Ellenbogen, S M Joshi and N Kitchen (2009). Development of cavernous haemangioma following radical chemoradiotherapy for nasopharyngeal carcinoma. The Journal of Laryngology \& Otology, 123, pp 925-927 doi:10.1017/ S0022215108003605

Request Permissions : $\underline{\text { Click here }}$ 


\title{
Development of cavernous haemangioma following radical chemo-radiotherapy for nasopharyngeal carcinoma
}

\author{
J R Ellenbogen, S M Joshi, N Kitchen
}

\begin{abstract}
Objective: We report an adult case of nasopharyngeal carcinoma treated with radical chemo-radiotherapy, with subsequent development of a histologically proved temporal cavernous haemangioma within the radiation field.

Method: Case report and review of the current literature concerning radiation-induced, secondary, space-occupying lesions.

Conclusion: The increasing role of radiotherapy in nasopharyngeal carcinoma treatment, together with improved patient survival, is likely to lead to radiation-induced, secondary, space-occupying lesions being encountered more frequently. We emphasise the need to be vigilant for this important but relatively rare complication, which has significant associated morbidity.
\end{abstract}

Key words: Cavernous Hemangioma; Radiotherapy; Nasopharyngeal Carcinoma

\begin{abstract}
Introduction
Although nasopharyngeal carcinoma (NPC) is a rare tumour, it accounts for more than 95 per cent of nasopharyngeal malignancies in adults and 20 to 35 per cent of those in children. ${ }^{1}$ It is a highly morbid disease with a poor survival outcome. The use of radiotherapy to treat head and neck tumours is increasing, either as primary or adjunctive therapy. The risk of radiation-induced, secondary, space-occupying lesions is a growing topic of investigation and concern.

We report an adult case of NPC treated with radical chemo-radiotherapy, with subsequent development of a histologically proved cavernous haemangioma within the radiation field. Such a case has not previously been reported in the literature. The increasing role of radiotherapy in NPC treatment, and improved patient survival rates, are likely to lead to these secondary tumours been encountered more frequently. We also review the current literature on this condition.
\end{abstract}

\section{Case report}

A 57-year-old woman presented in April 2000 with pain and deafness in the left ear and left facial numbness.

Examination under anaesthesia and imaging at that stage showed an extensive nasopharyngeal carcinoma (NPC) eroding through the pterygoid plate and invading the sphenoid and the posterior ethmoid sinus, with a lymph node present in the retropharynx. Biopsies confirmed an undifferentiated carcinoma of nasopharyngeal type, and further magnetic resonance imaging (MRI) identified extensive disease throughout the sphenoid, extending to the pituitary and middle cranial fossa. The disease did however appear to be extradural. Unusually for such an extensive primary tumour, the patient had no cervical lymphadenopathy.

The patient went on to receive radical chemo-radiotherapy. Following her treatment, further biopsies taken in June 2000 confirmed that she had residual disease within the nasopharynx.

The patient underwent further full adjuvant chemotherapy treatment with cisplatin and 5-fluorouracil. At this point, residual tumour was resected and gold grains were implanted at the primary site.

Following this treatment, the patient remained diseasefree. However, she suffered sequelae as a consequence of her radical treatment, namely, pain in the trigeminal nerve distribution on the left side, deafness in the left ear and loss of vision in the left eye.

In 2001, computed tomography scanning identified an area in the left temporal lobe suggestive of necrosis secondary to radiotherapy, and MRI scans taken between May 2006 and early 2007 showed that this area had developed into a large, cystic mass (Figure 1). In June 2006, a positron emission tomography scan, performed to exclude recurrence, showed no uptake within this region, despite normal uptake elsewhere in the brain.

In April 2007, the patient was admitted to The National Hospital for Neurology and Neurosurgery for a left temporal craniotomy for resection of the cystic tumour. At that time, she complained of her continued left facial pain, unsteady gait and decreased memory. Intra-operatively, a large, cystic lesion in the left temporal lobe with what appeared to be a cavernous haemangioma at the base was excised. Histological analysis confirmed a cavernous haemangioma and gliotic brain tissue.

After surgery, the patient's condition improved both physically and emotionally, and her pain was less intrusive.

\section{Discussion}

The typical radiation field for nasopharyngeal carcinoma (NPC) treatment encompasses the adjacent skull base, sphenoid sinus, middle cranial fossa and the soft tissue 


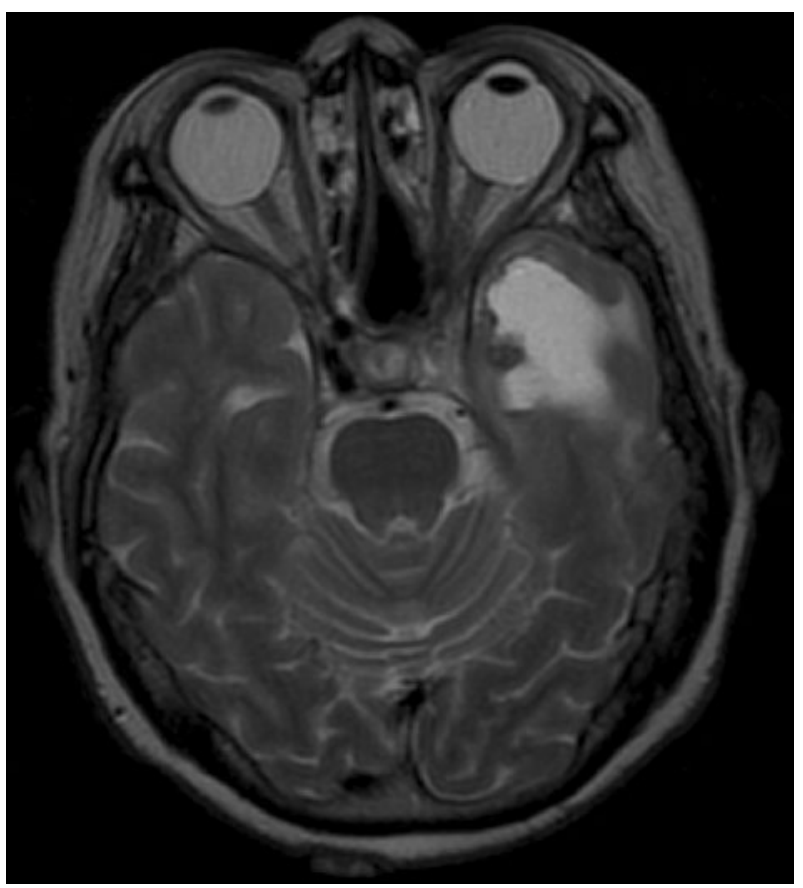

FIG. 1

Axial, T2-weighted magnetic resonance imaging brain scan, demonstrating the lesion.

juxtaposed to the nasopharynx. ${ }^{1}$ Patients undergoing a full course of radiotherapy for NPC will receive a dose of 66$70 \mathrm{~Gy}$ to this large area. This is above the $55 \mathrm{~Gy}$ at which the dose-response relationship between radiation dose and secondary induced tumour risk has been demonstrated to increase. ${ }^{2}$

The common complications of radiotherapy to the head and neck have been well documented. Some rarer complications which have been reported after NPC radiotherapy, with potentially serious consequences, include temporal bone necrosis and abscess formation, ${ }^{3}$ temporal bone tumours, ${ }^{4}$ sarcomas, ${ }^{2}$ and, in the current case, cavernous haemangioma. The five-year incidence of secondary primary tumours following radiotherapy for NPC has been shown to be 5.8 per cent. ${ }^{5}$

Cavernous haemangiomas are vascular malformations composed of dilated, thin-walled capillaries consisting of a single layer of endothelium and differing quantities of subendothelial fibrous stroma, with absence of smooth muscle and elastic fibres. These sinusoidal-type vessels are immediately in apposition to each other, without any recognisable intervening neural parenchyma. They can vary in size from punctate to several centimetres across, and can occur anywhere in the intracranial parenchyma, as well as in the spinal cord and on cranial and spinal nerve roots.

Although a benign vascular developmental malformation, cavernous haemangiomas have been identified to occur as a result of radiation therapy. Radiation-induced, de novo formation of cavernous haemangiomas is rarely reported, but recently has been observed with increasing frequency. The majority of such lesions have been observed in the male paediatric population. ${ }^{6}$ One study demonstrated a sixfold prevalence rate of cavernous haemangiomas in children aged between two to 11 years at the time of radiotherapy, compared with that cited in the literature for this population. The latency interval between radiotherapy and cavernous haemangioma development has been found to be three to 102 months (median 37 months). ${ }^{7}$
Cavernous haemangiomas have also been reported to occur in the radiation field of children, seven to 19 years after radiation treatment for paediatric brain tumours (medulloblastomas, ependymoma and midbrain astrocytoma). ${ }^{8} \mathrm{~A}$ review of de novo cavernous malformations of the central nervous system arising after radiotherapy identified a mean latency period until lesion detection of 8.9 years after a mean radiation dose of $60.45 \mathrm{~Gy}$, across all primary tumours in adults and children. ${ }^{6}$ Radiationinduced vascular malformations have been found to occur in a noticeably shorter time interval, compared with other benign, radiation-induced tumours.'

Although rare, these secondary tumours are associated with significant morbidity. Patients with cavernous haemangiomas may remain asymptomatic and unaware of their vascular lesion; however, they may alternatively present with symptoms of intracranial haemorrhage, seizures, progressive or transient neurological deficits, and headaches. The risk of haemorrhage has been suggested to be between 0.25 and 0.7 per cent per lesion per year. ${ }^{10,11}$

The pathophysiological mechanisms of radiation-induced cavernous haemangioma formation are not clearly understood. Various authors have suggested mechanisms predisposing to cavernous malformation secondary to radiation, including: genetic mutation; growth factor up-regulation; radiation-induced vessel wall necrosis; and vessel wall changes including cell swelling, hyalinisation, fibrosis and mineralisation. ${ }^{6,12}$ However, such theories are yet to be substantiated.

\section{- The increasing role of radiotherapy in} nasopharyngeal carcinoma (NPC) treatment, together with improved patient survival, is likely to lead to radiation-induced, secondary, space-occupying lesions being encountered more frequently

- This report describes an adult case of NPC treated with radical chemo-radiotherapy, with subsequent development of a cavernous haemangioma within the radiation field

- The authors emphasise the need to be vigilant for this important but relatively rare complication, which has significant associated morbidity

It is debatable whether radiation-induced cavernous haemangiomas develop from previously overlooked precursors or are, in fact, de novo malformations. The fact that they occur within the radiation field, as in our case, supports the theory that they arise de novo. ${ }^{2}$ Other supporting evidence lies in the fact that, in children less than 10 years of age, the length of the latency period between radiation and cavernous haemangioma formation has been shown to be dependent on the total radiation dose. ${ }^{13}$ In children, the higher the radiation dose, over $30 \mathrm{~Gy}$, the shorter the latency period; in adults, cavernous haemangiomas have been shown to develop only above a $30 \mathrm{~Gy}$ threshold. ${ }^{13} \mathrm{It}$ is unclear why cavernous malformations occur more frequently in children than adults after radiotherapy. The immature brain may be more sensitive to radiotherapyinduced changes than the mature brain. ${ }^{14}$

\section{Conclusion}

We report an adult case of nasopharyngeal carcinoma treated with radical chemo-radiotherapy, with subsequent development of a histologically proved temporal cavernous haemangioma within the radiation field. It is likely that, 
with the increasing use of radiotherapy and the associated increase in life expectancy, radiation-induced secondary tumours will become more commonplace. It is vital that clinicians remain vigilant for this important but relatively rare complication, as early detection can enable timely intervention and a reduction in potentially significant morbidity.

\section{References}

1 Jeyakumar A, Brickman TM, Jeyakumar A, Doerr T. Review of nasopharyngeal carcinoma. Ear Nose Throat J 2006;85:168-74

2 King AD, Ahuja AT, Teo P, Tse GMK, Kew J. Radiation induced sarcomas of the head and neck following radiotherapy for nasopharyngeal carcinoma. Clin Radiol 2000; 55:684-9

3 Cheng KM, Chan CM, Fu YT, Ho YW, Tsang YW, Lee MK et al. Brain abscess formation in radiation necrosis of the temporal lobe following radiation therapy for nasopharyngeal carcinoma. Acta Neurochir (Wien) 2000;142. 435-41

4 Goh YH, Chong VF, Low WK. Temporal bone tumours in patients irradiated for nasopharyngeal neoplasms. J Laryngol Otol 1999;113:222-8

5 Kong L, Lu JJ, Hu C, Guo X, Wu Y, Zhang Y. The risk of secondary primary tumors in patients with nasopharyngeal carcinoma after definitive radiotherapy. Cancer 2006;107: 1287-93

6 Nimjee SM, Power CJ, Bulsara KR. Review of the literature on de novo formation of cavernous malformations of the central nervous system after radiation therapy. Neurosurg Focus 2006;21:1-6

7 Burn S, Gunny R, Phipps K, Gaze M, Haywood R. Incidence of cavernoma development in children after radiotherapy for brain tumors. $J$ Neurosurg 2007;106:379-83
8 Baumgartner JE, Ater JL, Ha CS, Kuttesch JF, Leeds NE, Fuller GN et al. Pathologically proven cavernous angiomas of the brain following radiation therapy for pediatric brain tumours. Pediatr Neurosurg 2003;39:201-7

9 Amirjamshidi A, Abbassioun K. Radiation-induced tumors of the central nervous system occurring in childhood and adolescence. Childs Nerv Syst 2000;16:390-7

10 Robinson JR, Awad IA, Little JR. Natural history of the cavernous angioma. $J$ Neurosurg 1991;75:709-14

11 Curling OD, Kelly DL, Elster AD, Craven TE. An analysis of the natural history of cavernous angiomas. J Neurosurg 1991;75:702-8

12 Furuse M, Miyatake SL, Kuroiwa T. Cavernous malformation after radiation therapy for astrocytoma in adult patients: report of 2 cases. Acta Neurochir (Wien) 2005; 147:1097-101

13 Heckl S, Achoff A, Kunze S. Radiation-induced cavernous hemangiomas of the brain. Cancer 2002;94:3285-91

14 Gaensler EH, Dillon WP, Edwards MS, Larson DA, Rosenau W, Wilson CB. Radiation-induced telangiectasia in the brain simulates cryptic vascular malformations at MR imaging. Radiology 1994;193:629-36

Address for correspondence:

Mr N Kitchen,

Consultant Neurosurgeon,

The National Hospital for Neurology \& Neurosurgery, London, WC1N 3BG, UK.

E-mail: neil.kitchen@uclh.nhs.uk

Mr N Kitchen takes responsibility for the integrity of the content of the paper.

Competing interests: None declared 